\title{
Research on grab digging process based on EDEM
}

\author{
Lei $\mathrm{Mei}^{1, \mathrm{a}}$, Jiquan $\mathrm{Hu}^{1, \mathrm{~b}}$, Jianguo $\mathrm{Yang}^{1, \mathrm{c}}$ and Jianming Yuan ${ }^{1, \mathrm{~d}}$ \\ ${ }^{1}$ School of energy and power engineering, Wuhan University of Technology, Wuhan 433063; \\ 2 School of Logistics Engineering, Wuhan University of Technology, Wuhan 433063. \\ ameilei001007@163.com, b hjq580818@126.com, 'jgwhut@126.com, ${ }^{\mathrm{d}}$ whtu_yjm@163.com
}

Keywords: grab, dig materials, EDEM simulation.

\begin{abstract}
Movement of the grab excavation process and stress state is the key to conduct large grab design. In this paper, discrete element theory is used to the simulation study of the large marine dredging digging grab process. Through the simulation of large-scale grab EDEM without deep reclaiming process, we get all the key parts of the grab variation of the force. Provide reference to reasonably determine speed of, hopper shape, arc discharge baffle structure, in order to design Grab mechanism design and improve the efficiency and reduce energy consumption.
\end{abstract}

\section{Introduction}

In the work process of grab, it is more complex about the law of motion that material being excavated, lifting, as well as material and material interaction between the grab device [1-2]. Discrete Element Method (DEM) to grab digging process provides an effective analysis tool. Theoretical basis of discrete element method is Newton's laws of motion, Hertz contact theory and bulk physical theory, This method granular body into a collection of discrete units [3], Establish a different mechanical constitutive relation between the equations of motion for each unit combination granules, use dynamic relaxation method get the iterative solver, get the relationship between different granules force and displacement, obtain The overall state of motion of granular body and particle size of the geometry of the force.

In this paper, we use the discrete element method (DEM) and the software of discrete element analysis software EDEM get the simulation research of Grab on large marine dredging digging process. By EDEM simulation of large grab's digging material process, guide the design of Grab bodies, determine reasonably speed, hopper shape, arc discharge baffle structure, in order to improve efficiency and reduce energy consumption.

By EDEM simulation software, get draw force conditions of Grab and the volume of material excavated at the depth of each part when the two materials at different initial insertion excavation, assess the key factors affecting the performance of its mining. By analyzing the variation of the force grapples mining process, and provide a reference for grabs structural design.

According to the work situation of grab, This article intends to take a hard clay and sand reef types of materials as mining objects, Its associated physical and mechanical properties as shown in Table $1[4]$.

Narrow the size of 200 square hydraulic grab 4: 1, Build three-dimensional modeling in mechanical modeling software SOLIDWORKS. The agency is mainly composed of left watercress and right watercress as well as hydraulic cylinder and rod constitute. Figure 1 shows a hydraulic grab from the fully open to closed during exercise.

Contact model particles and particles, particles and boundary geometry, the direction and magnitude of gravity, physical material particles and geometry, Inter-particle collisions between particles and the geometry of the recovery coefficient static coefficient of friction and rolling friction coefficient [5]. Details as follows: 
(1) The particle size and shape

The simulation of particle objects are coral reef soil, the actual coral reef is nearly spherical shape soil, Therefore, EDEM simulation use spherical particles. According to particle characteristics supplied parameters, The particles distribution ratio is shown in Table 2.

Four types of particles in the discrete element simulation software EDEM are set in radius (the radius of the particles generalized here) normally distributed with mean 1 times the radius variance $1 \mathrm{~mm}$.

(2)the material properties and the geometry of the particles.

(4) contact model

Discrete Element Method imitation the propagation in particle collection, Particle motion would inevitably lead to the collision between the particles and produce force, displacement and deformation. Contact model is to describe the physical model of the relationship between the three [6]. In this simulation, Hertz-Mindlin (no slip) [7,8]are used between the particles and the particles, contact model between particles. This contact model is based on Hertz-Mindlin contact theory, more in line with the contact and the motion of the particles in this simulation. (5) simulation program.

In the research and analysis of grab agency conducted mining process, in order to study different insertion depth of grab and crawls impact resistance, We select five insertion depths. As shown in Table 5.

In the working process, the maximum opening is $156.4^{\circ}$, complete closure time is $36 \mathrm{~s}$. The average closed angular velocity $2.17 \mathrm{deg} / \mathrm{s}$.

(3) contacting particles and geometry attributes

Mining process simulation: grab two bucket body turned from $0^{\circ}$ to $78.2^{\circ}$. After the treatment, we obtain the next five different insertion depth. The total number and the total mass of particles within a single hopper in each data storage time point on the entire mining process, each member of body suffer force and fighting body fit to withstand the moment, The data can be used to analyze trends hopper mining capacity and suffered resistance. Figure 2,3,4,5,6 are simulation schematics in different digging depth successively.

The teeth of grab material is mainly used for the destruction of the original structure, make the material loose and easily picking. The following changes in the force curve due to the relatively small size of the bucket teeth, which is more sensitive to material changes in reaction,It will appear "jag gies,"in the local curve. When in one direction the force is small ,it will also be prone to "jag gies" ,but the overall trend curve can be referenced.

Figure 7 shows the total force of bucket teeth suffered under five different insertion depths with grab changes during closing, A represents a reef sand, b represents the hard clay. Five curves under the same kinds of materials have similar variation are showed in the figure, Material force of bucket teeth are gradually decreased during the grab closing.

The plate of grab mainly bears gravity from the hopper of materials, friction of materials and in the process of digging and the pushing resistance effect of excavated soil.

Figure 8 shows the total force of floor which suffered reef sand and hard clay under five different insertion depths with grab changes during closing ,a represents a reef sand, b represents hard clay. Five curves under the same kinds of materials have similar variation are showed in the figure, the total force of floor of the grab are first increases and then leveled off.

Side plate are mainly bears the resistance when the side edge cuts materials and the friction effect of the material.

Figure 9 shows the total force of side plate the grab suffered under five different insertion depths with grab changes during closing, are presents a reef sand, b represents hard clay. Five curves under the same kinds of materials have similar variation are showed in the figure, the total force of side board of the grab are first slightly increased and then sharply decreases.

The body is mainly used for accommodating material .It bears the gravity from the hopper of materials, friction outside bucket as well as static soil pressure and pushing resistance of the soil. 
Figure10 shows the total moment of the body of the grab suffered under five different insertion depths with grab changes during closing , a is presents a reef sand, b represents hard clay. Five curves under the same kinds of materials have similar variation are showed in the figure, it looks like a parabola ,it firstly increases and then decreases and reaches a maximum in the opening of about 50\%.

During the mining process of grad, material will have some spill and Excavated material surface is also due to material flow ,so that the excavated material surface is not a simple arc shape.

Figure 11shows different materials-sectional shape in different insert depth and the corresponding volume of excavated material, As shown in Table 6 so that provide a reference for the theoretical analysis.

By discrete element method simulation, this article obtain the variation law of digging resistance and the filling level of the grab under different insertion depths with grab changes during closing. The analysis reveals the similar trends between simulation and theoretical results. Each component of the force is consistent with the actual situation and verify the reliability of the theoretical calculation method; At the same time, Insertion depth can be preferably choosed under guarantying the mining capabilities. Overall, Using EDEM software crawl grab simulation can provide a meaningful reference for the design of actual Grab calculation and application.

\section{Physical and mechanical properties of materials}

Table 1 Physical and mechanical properties of the material excavated

\begin{tabular}{|c|c|c|c|c|c|}
\hline \multicolumn{3}{|c|}{ Mechanical index } & \multicolumn{2}{|c|}{ Type of material } & \multirow{2}{*}{$\begin{array}{l}\text { related indicators and } \\
\text { impact factor of Grab } \\
\text { force }\end{array}$} \\
\hline name & symbol & unit & Hard clay & Reef sand & \\
\hline Natural bulk density & $\gamma$ & $\mathrm{KN} / \mathrm{m} 3$ & $11.4-13.4$ & $11.3-15.2$ & $73.02 \%$ \\
\hline SPT blow count & $\mathrm{N}$ & - & $8-15$ & $12-30$ & - \\
\hline Porosity & $\mathrm{n}$ & $\%$ & $45-60$ & $40-59$ & - \\
\hline Relative density & Dr & - & $0.67-1$ & $0.33-0.67$ & - \\
\hline Moisture & W & $\%$ & $10-30$ & $12.8-22.2$ & - \\
\hline $\begin{array}{l}\text { Natural slope } \\
\text { (underwater) }\end{array}$ & $\theta 0$ & $\circ$ & - & 29.5-36.6 & - \\
\hline Natural slope (dried) & $\theta$ & $\circ$ & - & $30.5-42.0$ & - \\
\hline Cohesion factor & c & $\mathrm{KN} / \mathrm{m} 2$ & $20.5-28.1$ & $24.8-44.3$ & $37.18 \%$ \\
\hline Density rate of change & Ky & $\mathrm{KN} / \mathrm{m} 3$ & 0 & 0 & - \\
\hline Surface density & $\gamma 0$ & $\mathrm{KN} / \mathrm{m} 3$ & $11.4-13.4$ & $11.3-15.2$ & $22.81 \%$ \\
\hline $\begin{array}{l}\text { Mining drag } \\
\text { coefficient }\end{array}$ & $\mathrm{Kb}$ & - & $4.5-5.7$ & $5.2-8.3$ & $70.26 \%$ \\
\hline Internal friction angle & $\varphi 0$ & $\circ$ & $22-30$ & $37-45$ & $15.1 \%$ \\
\hline $\begin{array}{c}\text { The average particle } \\
\text { size }\end{array}$ & $\mathrm{a}$ & $\mathrm{mm}$ & $0.075-0.5$ & $0.5-2$ & $0.38 \%$ \\
\hline
\end{tabular}


Parameter setting of EDEM simulation in the process of hydraulic grab digging

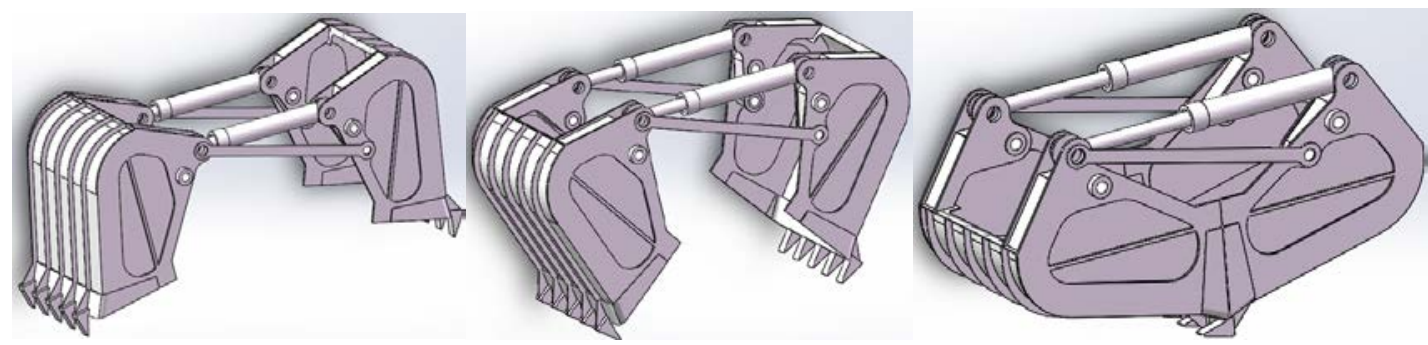

Fig.1 Hydraulic grab simulation model diagram

Table 2 Particle size distribution table

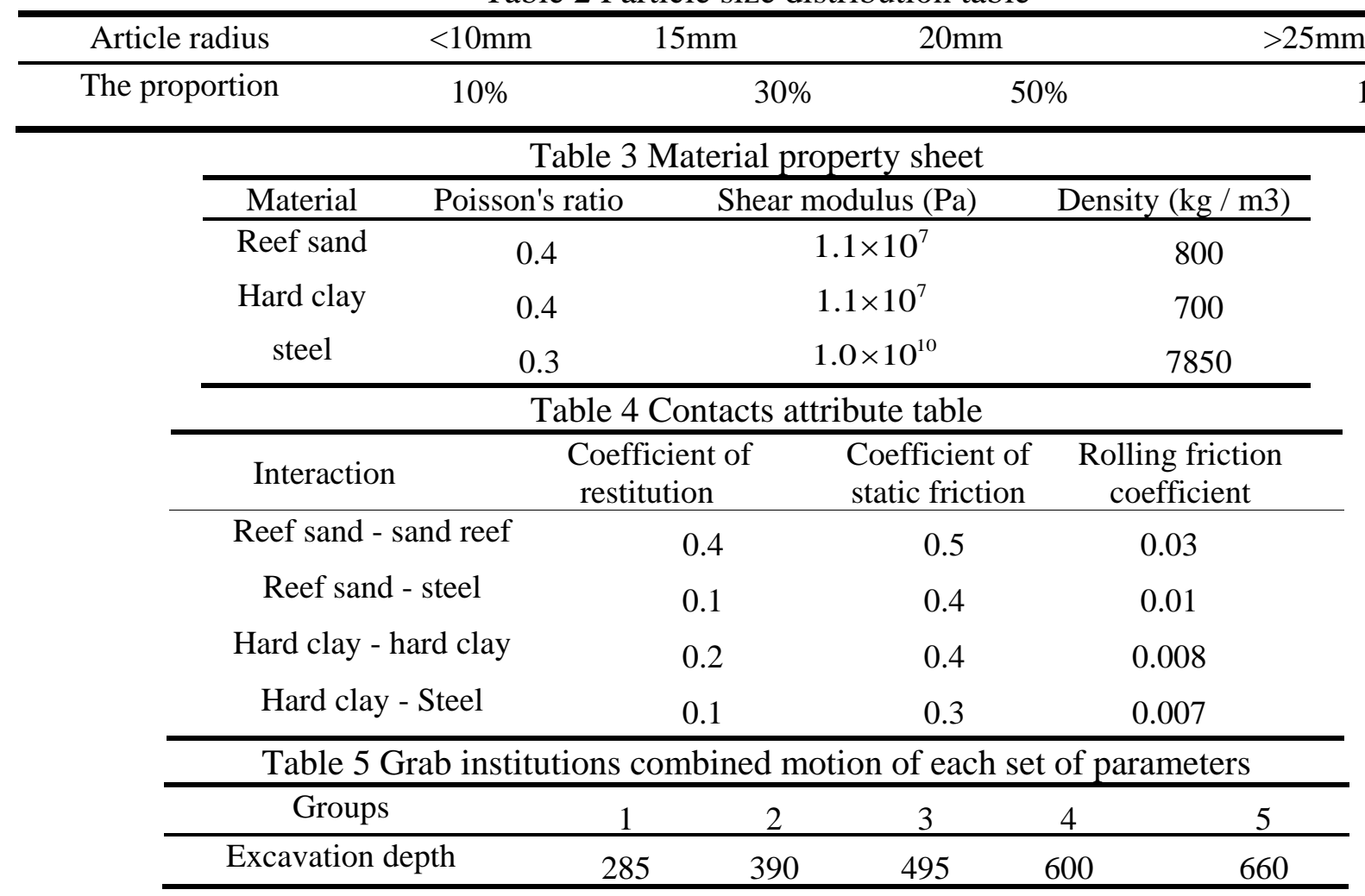

\section{Crawling process simulation results}
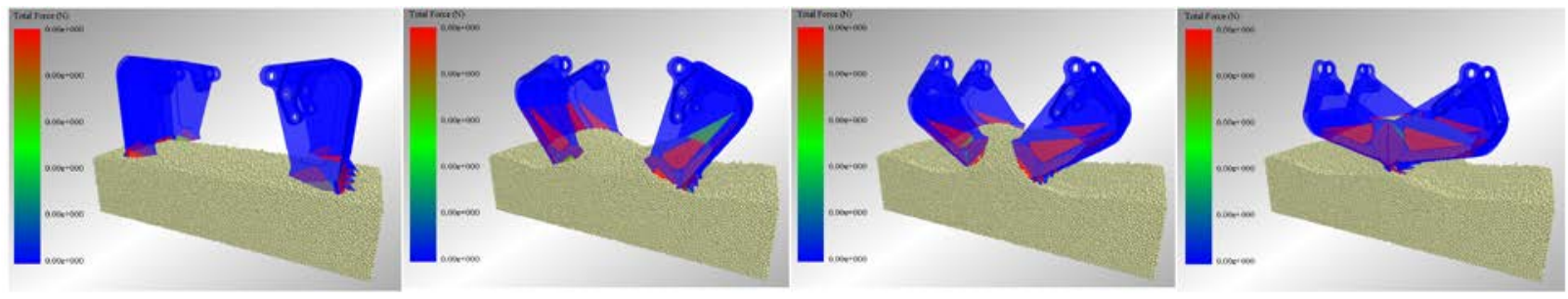

Fig.2 insertion depth 285mm, bucket body closing process

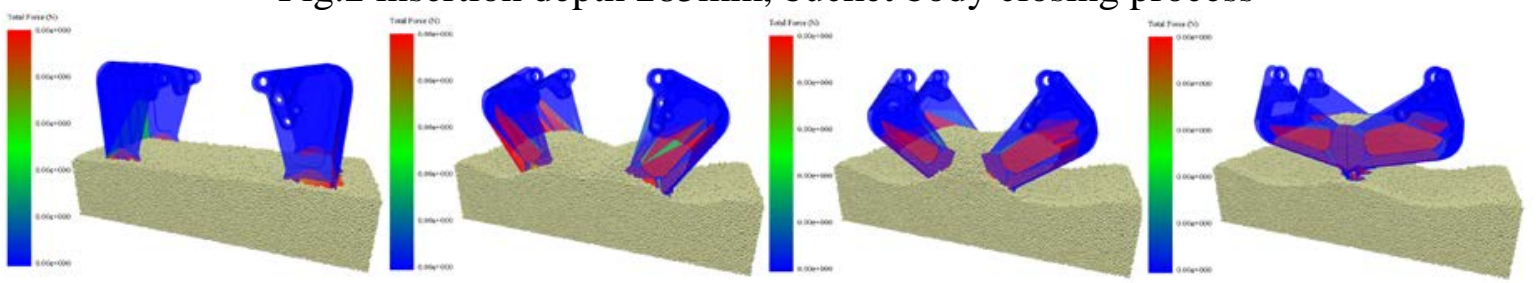

Fig.3 insertion depth 390mm, bucket body closing process 


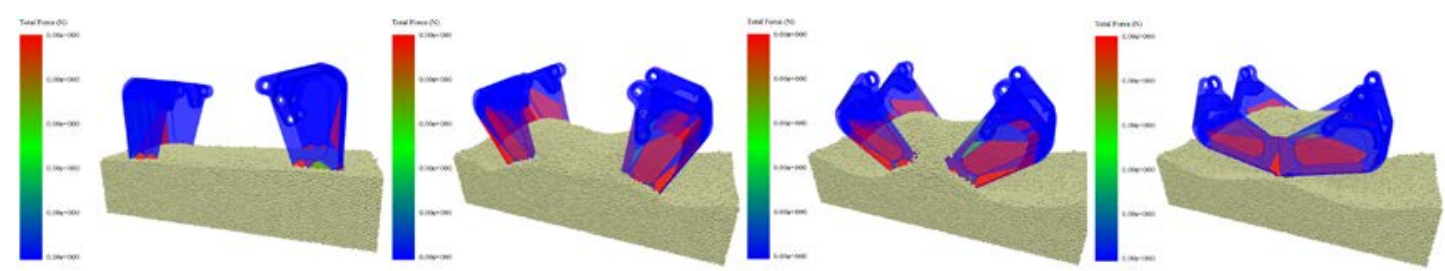

Fig.4 insertion depth 495mm, bucket body closing process

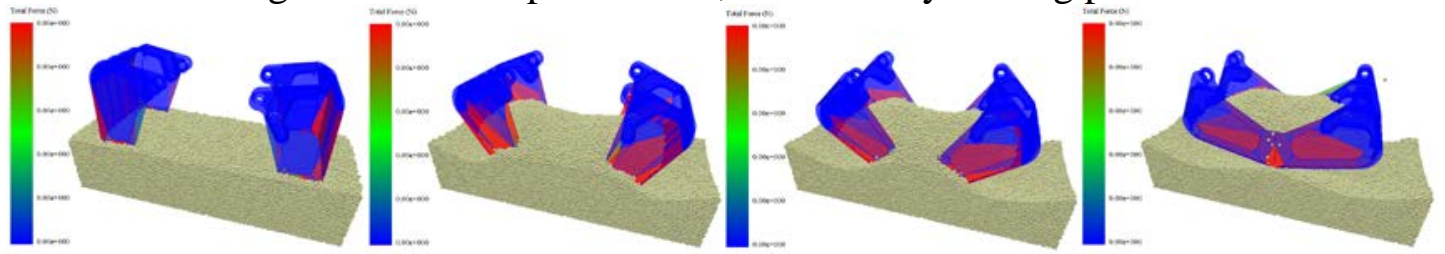

Fig.5 insertion depth 600mm, bucket body closing process

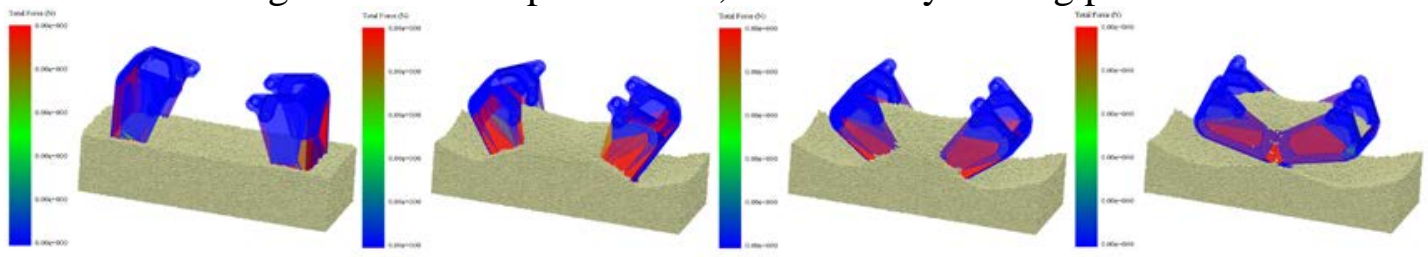

Fig.6 insertion depth 660mm, bucket body closing process

Stress Analysis of bucket during mining process

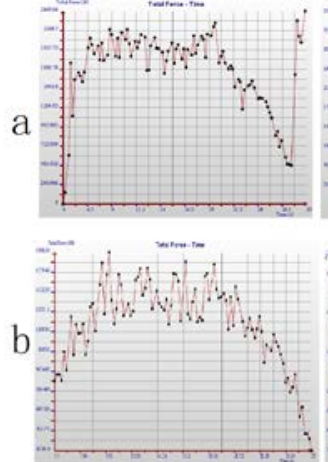

$285 \mathrm{~mm}$
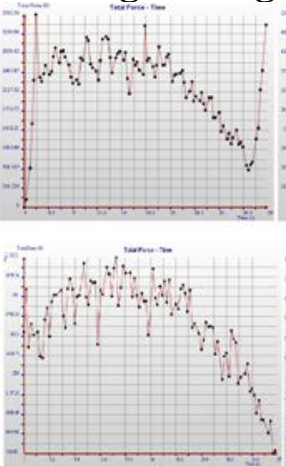

$390 \mathrm{~mm}$
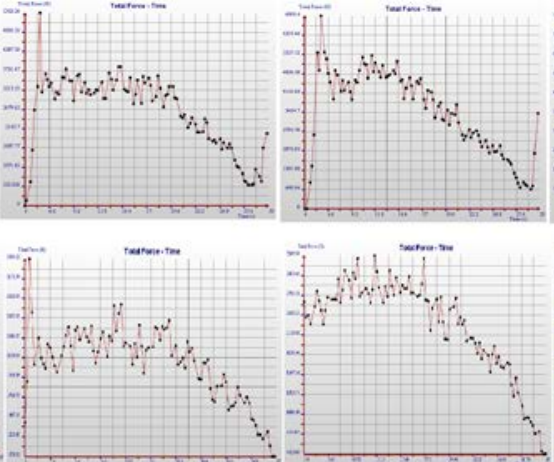

$495 \mathrm{~mm}$

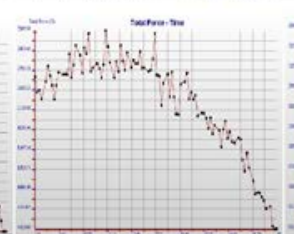

$600 \mathrm{~mm}$
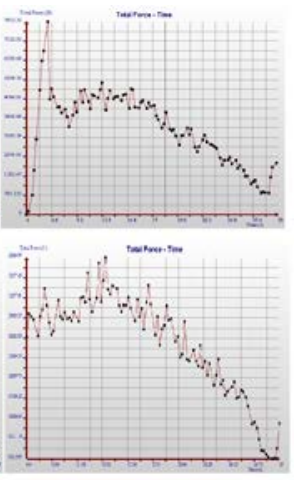

$660 \mathrm{~mm}$

Fig. 7 the total force of bucket teeth suffered under five different insertion depths with grab changes during closing

Stress Analysis of floor during mining process
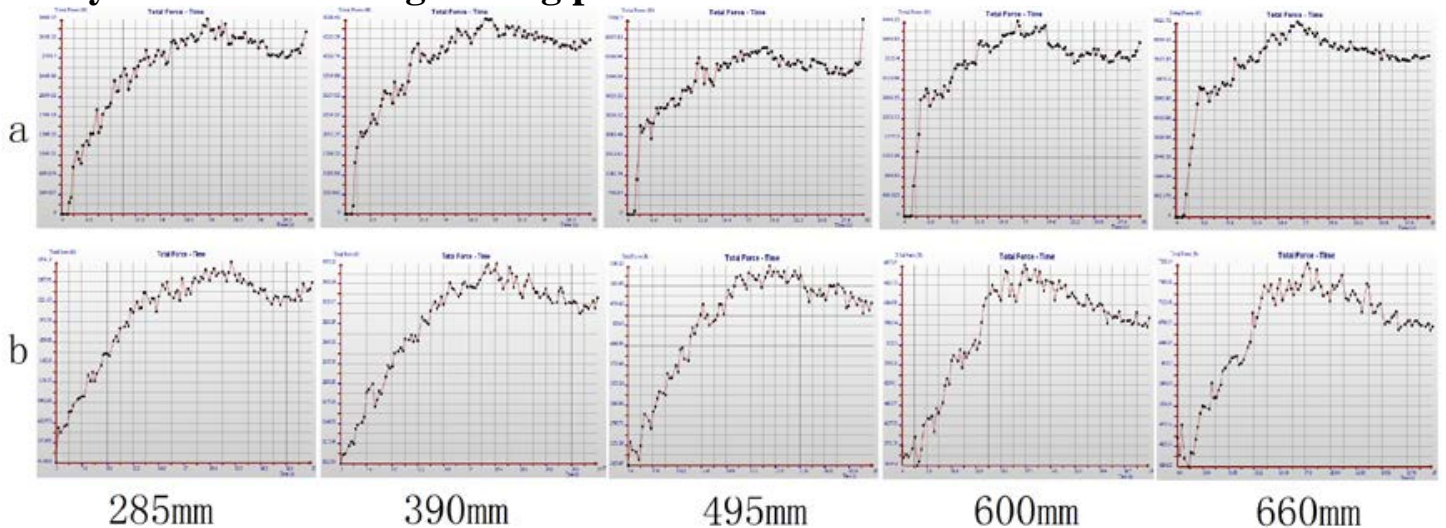

$390 \mathrm{~mm}$

$495 \mathrm{~mm}$

$600 \mathrm{~mm}$

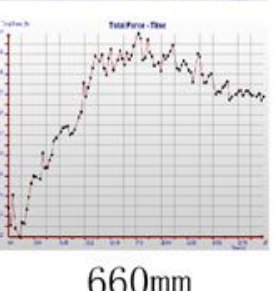

Fig. 8 the total force of floor of the grab suffered under five different insertion depths with grab changes during closing 
Stress Analysis of side board during mining process

a
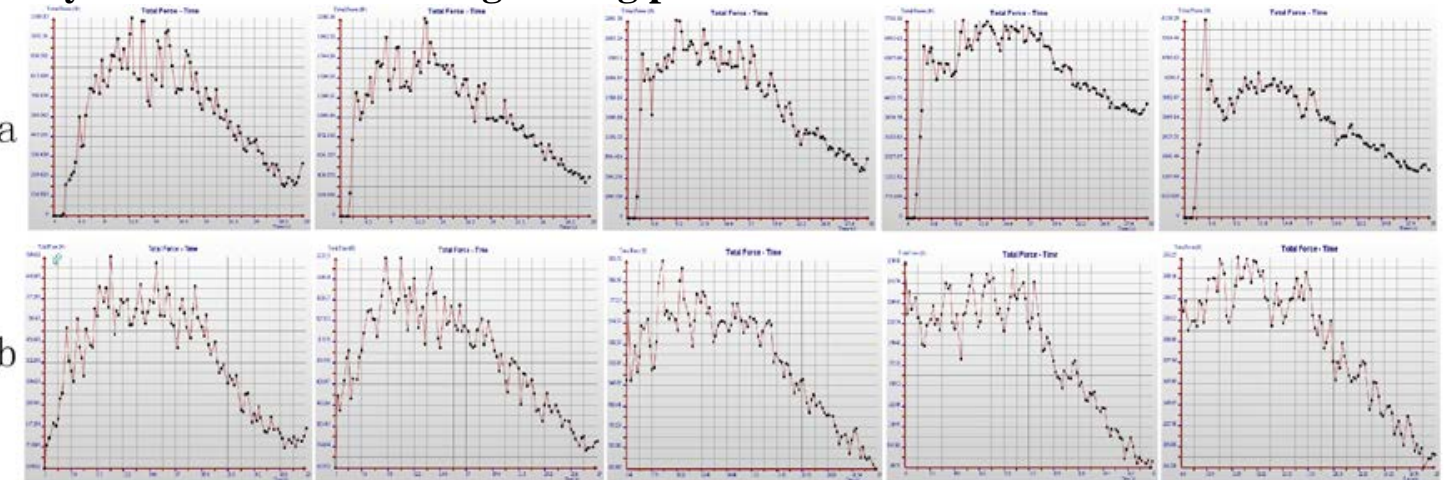

$285 \mathrm{~mm}$

$390 \mathrm{~mm}$

$495 \mathrm{~mm}$

$600 \mathrm{~mm}$

$660 \mathrm{~mm}$

Fig. 9 the total force of side plate the grab suffered under five different insertion depths with grab changes during closing

\section{Stress Analysis of body during mining process}
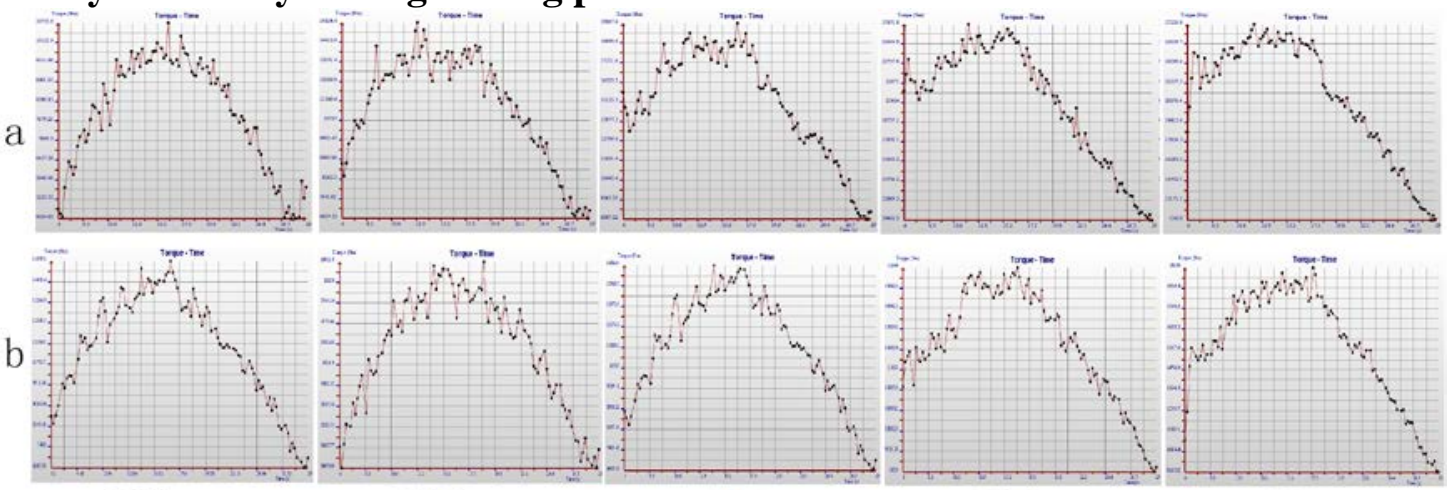

$285 \mathrm{~mm}$

$390 \mathrm{~mm}$

$495 \mathrm{~mm}$

$600 \mathrm{~mm}$

$660 \mathrm{~mm}$

Fig.10 the total moment of the body of the grab suffered under five different insertion depths with grab changes during closing

\section{Trajectory Analysis of Grab Mining}

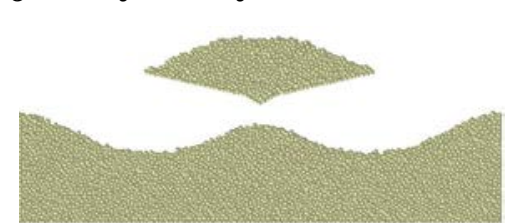

a) insert depth $285 \mathrm{~mm}$

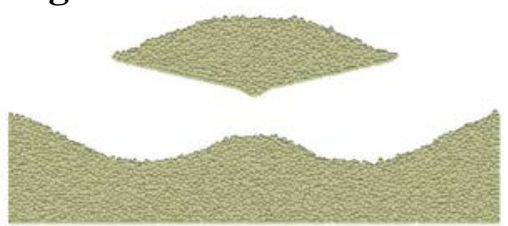

b) insert depth $390 \mathrm{~mm}$

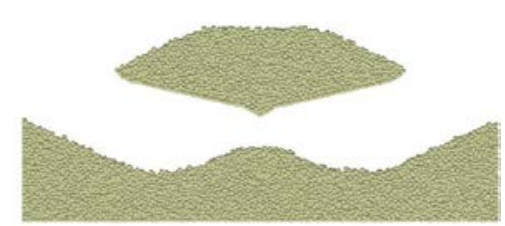

c) insert depth $495 \mathrm{~mm}$

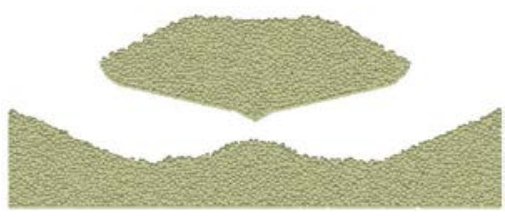

d) insert depth $600 \mathrm{~mm}$

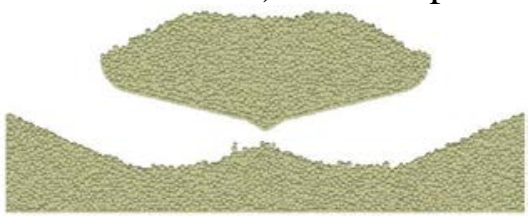

e) insert depth $660 \mathrm{~mm}$

Fig.11 different materials-sectional shape in different insert depth Table 6 The volume of excavated materials in different insert depth

\begin{tabular}{cc}
\hline Initial insert depth material $(\mathrm{mm})$ & The volume of excavated materials $(\mathrm{m} 3)$ \\
\hline 285 & 0.84 \\
390 & 1.27 \\
495 & 1.68 \\
600 & 2.06 \\
660 & 2.25 \\
\hline
\end{tabular}




\section{References}

[1] $\mathrm{Hu}$ Li. Particle discrete element simulation technology and realization in mechanical product design, D. Wuhan: Power and Mechanical University, 2013.

[2] Wu Zuowei. Implementation and Simulation of dredging grab flat digging job, D. Wuhan: Wuhan University of Technology Logistics Engineering, 2014.

[3] Li Ran. Based Reasoning Research and Development grab three-dimensional design system, D. Wuhan: Wuhan University of Technology Logistics Engineering, 2005.

[4] Wang xinzhi, WANG Ren, Meng JianShan, Chen Jianwen. Study on mechanical properties of limestone reef coral reefs of Nansha Islands, J. Mechanics and Geotechnical Engineering,2008,27 (11):2221-2226.

[5] Owen P J, Cleary P W. Prediction of screw conveyor performance using the discrete element method (DEM), J. Powder Technology, 2009, （193） : 274-288

[6] Cleary P W. DEM modelling of particulate flow in a screw feeder, J. Progress in Computational Fluid Dynamics, 2007, 7(Nos. 2/3/4):128-138.

[7] Zhang Haining, Dredging grab mechanical properties Simulation Analysis and Experimental Research, D. Wuhan: Wuhan University of Technology Logistics Engineering, 2014.

[8] Hu Guoming etc.Discrete Element Method Simulation of particle analysis system, M. Wuhan University of Technology Logistics Engineering, 2010. 